\title{
THEORETICAL GUIDELINES REGARDING PERFORMANCE AUDIT IN THE MILITARY ORGANIZATION
}

\author{
Marius MILANDRU, Sebastian FLOȘTOIU \\ "Nicolae Bălcescu" Land Forces Academy, Sibiu, Romania \\ mnmilandru@yahoo.com, flostoiu.sebastian@gmail.com
}

\begin{abstract}
In the contemporary organizational environment, the internal public audit allows the management to develop its action capacity, thus ensuring that its strategy is correctly put in practice and the effects related to economy, efficiency and effectiveness are the expected ones. The implementation of the internal audit in the military organization represents a continuous and modern action that is part of the general effort to streamline the management of public institutions in Romania. The audit solutions must contribute to strengthening the stability of the military institution and to achieving its objectives, both domestically and internationally, in terms of anticipation and proper risk management, optimal use of the allocated resources and compliance with the existing legal framework.
\end{abstract}

Keywords: military organization, internal public audit, resources, performance, solutions, recommendations

\section{Introduction}

There are currently several approaches for the definition of public internal audit, but the one developed by the Institute of Internal Auditors is generally accepted. According to their definition, "internal audit is an independent activity of objective assurance and counselling, designed to add value and improve the operations of an organization; it assists an organization in achieving its objectives through a systematic and methodical approach that evaluates and improves the effectiveness of risk management, control and governance processes" [1].

In our country, initially, the public internal audit was implemented by Government Ordinance no. 119/1999 concerning the internal public audit and the preventive financial control, and subsequently, the approval of a distinct law for this activity, respectively Law no. 672/2002 regarding the internal public audit was adopted. Thus, in 1999, Romania legislated the internal audit for public entities. "This absolute premise has produced many debates, many reorganizations of control and its separation from auditing activities. The shaping of the internal audit imposed the definition of the external audit as well" [2]. The amendments brought by Law no. 191/2011 for the amendment and completion of Law 672/2002, amendments that also involved the republishing of Law no. 672/2002 were significant in the legislation related to the internal public audit. At the same time, it was necessary to repeal the Norms approved by the Order of the Minister of Public Finance no. 38/2003 and the Order of the Minister of Public Finance no. 1702/2005 and the approval of new norms, which took the form of General 
Norms regarding the exercise of the internal public audit activity, approved through Government Decision no. $1086 / 2013$. Over time, the regulatory framework was completed by Government decisions or ministerial orders [3].

References are often made to resource optimization audit, as well as to performance audit, in connection with the analysis of the use of public assets. Performance auditing can occasionally be interpreted as going beyond specific aspects of resource optimization, including the achievement of the objectives of the military organization. The terms "performance" and "resource optimization" are frequently used interchangeably by the vast majority of auditors.

Performance audit assesses the results, analyzes the economy, effectiveness, efficiency and indicators (optimization of the means in relation to the objectives, relevance of the structures, methods, quality of the managerial act and the results obtained) [4]. It examines whether the criteria choose for the implementation of the objectives and tasks of a public institution are correct for evaluating the results and establish whether the results are in line with the objectives.

\section{Specific elements of performance audit}

The performance audit is an objective and systematic examination of activities, systems and management standards of the military organization in order to assess the extent to which that entity, in an attempt to achieve predefined goals, has used its assets in economical, efficient and effective.

Although performance audit can be very comprehensive, it will apply to:

- activities which require a high level of resources;

- projects with a potential risk of not achieving objectives;

- issues of interest or concern to top management.

Independent performance reviews indicate the extent to which the management of military entities, using the resources necessary to achieve the organization's goals, has achieved its policies, principles or standards in an economical, efficient and effective manner.

A secondary objective of performance audit is to improve the organization's performance and optimize the use of resources and to help management take the necessary steps to improve control systems and tools.

The performance audit represents the independent evaluation of the degree of achievement of the economy, efficiency, effectiveness and fulfillment of the desired results.

The three elements of resource optimization can be defined in various forms, as follows: a) economy refers to the reduction of the costs of the resources used (personnel, materials and equipment) in an activity carried out in order to achieve the objectives and to the compliance of these resources with the principles and practices of optimal administration and with the policies of performant management.

An economically functioning military structure purchases the input resources in the right quantities, at the appropriate quality standards, and by paying the lowest price.

In conclusion, economy represents minimization of the cost of resources used in an activity, without compromising their quality, i.e. economic spending, while maintaining quality.

The following calculation relationship is used to measure economy:

\begin{tabular}{|c|c|c|}
\hline Economy & $\begin{array}{c}\text { Consumed } \\
\text { resources } \\
\left(R_{c}\right)\end{array}$ & $\begin{array}{c}\text { Scheduled } \\
\text { resources } \\
\left(R_{p}\right)\end{array}$ \\
\hline (Econ) & $\begin{array}{c}\text { Obtained } \\
\text { results } \\
\left(\mathrm{Re}_{\mathrm{o}}\right)\end{array}$ & $\begin{array}{c}\text { Schedules } \\
\text { results } \\
\left(\mathrm{Re}_{\mathrm{p}}\right)\end{array}$ \\
\hline
\end{tabular}

The favorable case is considered when Econ $<1$. 
For example, as applied to the military organization, it translates as follows:

- for example, certain standard items, necessary to the academies, schools, or military hospitals, of a certain quality, and which are acquired at the best cost;

- the cost of a vehicle compared to a similar quality model.

Thus, we can appreciate that a military unit does not meet this indicator when we find weaknesses in the procurement system or too many personnel related to the concrete activities of the entity.

In such situations, it is required to resize the number of employees according to the real needs of the audited entity and implement the public procurement system in accordance with the regulations in force.

b) Efficiency takes into account the relationships between the goods and services provided (results) and the resources used to produce those (inputs).

An efficient entity produces the maximum results, using a certain set of resources, or uses a minimum amount of resources to obtain a result of a certain quality and quantity. This will be reflected in expanded productivity and lower unit costs.

In conclusion, efficiency is correlated with profitability and productivity, being the expression of the relationship between the recorded results and the resources introduced in the system: maximizing the outputs/results by using the minimum inputs/resources.

The following calculation relationship is used to measure efficiency:

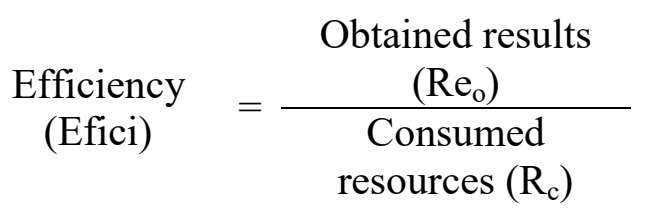

The convenient case is considered when the Achieved Efici> Scheduled Efici or an increase in dynamics is recorded.

In order to understand the importance of this element of performance we will discuss the following examples:
- we consider efficiency is improved when the unit cost of training a military or providing medical treatment has been reduced in time, or when, without committing additional resources, more students are trained in military educational institutions or more possibilities are available for treatment;

- reducing the cost of repairing and maintaining equipment, such as aircraft, military ships, vehicles, computers or copiers, is a signal of efficiency.

c) Effectiveness refers to the achievement of objectives (specific planned achievements) or predefined goals whose actual impact (the result achieved) can be compared with the desired impact (objectives). The use of a wide variety of tools and indicators for measuring performance will facilitate the evaluation of the effectiveness of an entity.

In conclusion, effectiveness means ensuring that the desired results/objectives/targets//policies have been successfully achieved (wise spending).

Effectiveness is measured with the help of the following calculation relationship:

$$
\begin{gathered}
\text { Effectiveness } \\
(\text { Efica })
\end{gathered}=\frac{\begin{array}{c}
\text { Obtained results } \\
\left(\mathrm{Re}_{\mathrm{o}}\right)
\end{array}}{\begin{array}{c}
\text { Scheduled results } \\
\left(\mathrm{Re}_{\mathrm{p}}\right)
\end{array}}
$$

The favorable case is when Efica $\geq 1$.

Examples of effectiveness may be:

- decrease in the rate of illness as a result of the medical care provided;

- when an item or service purchased is considered adequate to the purpose.

A specific aspect of the performance audit is the analysis of the side effects of an ongoing program by an entity (for example: the effects on the environment of the destruction of hazardous waste by burning them).

Performance analysis can be used to cover all types of projects/activities/programs and can be applied equally to certain sectors or to the military organization as a whole. 


\section{Performance audit procedures}

A performance audit program must be rigorously planned if it is to be effective. Planning is the way in which the audit objectives are identified, ranked and included in the general program of activity in order to evaluate the potential of the audit structure and to estimate the audit activities that will be carried out. The planning process leads to fair decisions about the nature, extent and timing of the performance audit to be performed.

The strategic planning process for internal audit units must be materialized in specific performance audit programs, which must be based on risk assessment.

When assessing the risks, the following criteria will be taken into account:

- the importance of the performance of the activity in achieving the general objectives of the military organization;

- the complexity of success indicators and their measuring tools;

- the level of interdependence with other systems / activities towards achieving the objectives;

- the volume / value of the resources used in the activity and the waste potential.

An important role is played by strategic planning, whose purpose is to establish the future of the performance audit program, the priorities and resources needed to carry it out.

Strategic plans are focused forward, over a 3 -year period, and is aimed at identifying long-term opportunities. Moreover, it may include more detailed proposals for shortterm audit missions. The plans involve procedures for identifying, prioritizing, and selecting possible areas for performance auditing, which should be reviewed and updated whenever necessary.

Proper strategic performance audit planning will ensure:

- the existence of an effective performance audit program;

- a complete and well-planned audit program;

- correct setting of priorities;
- optimal distribution of resources to areas with maximum impact;

- monitoring the implementation of the approved audit program;

- carrying out each mission as efficiently as possible.

Planning the approach of each performance audit mission is a very important step that must be completed before the on-site intervention. Audit teams must have a thorough knowledge of the topic or area to be audited.

Mission proposals that are subject to the initial period of strategic planning must be accompanied by very detailed information, because this ensures that they a high chance of being confirmed as areas to be audited.

The first stage in the process of understanding and deepening the area to be audited is the preliminary research. It is used to confirm or refute the need for a full audit of the area identified in the strategic planning stage. If the audit continues, the preliminary investigation must define the future course of the mission. It must also recommend precise objectives and tasks for a full audit. The preliminary research must be very concise, but at the same time sufficient to allow a decision to be taken on a full audit. The conclusions reached must be supported by adequate, relevant, and reliable evidence.

On-site intervention involves the examination and analysis of documents, visits to the organization and discussions with the responsible staff. Sometimes specialized assistance and counseling is needed when it comes to highly specialized areas, such as health services. The duration of the preliminary research will depend on the circumstances and complexity of the audited domain.

Techniques and tools taken from other disciplines must be used for the proper implementation of performance audit. The techniques chosen must be best suited to the needs and circumstances of a particular audit mission. 
Written materials are important sources of audit evidence and are an essential part of performance audit.

Interviews and discussions with staff are the main methods of gathering evidence.

All performance studies use some type of interview to collect information and establish facts. To be successful, interviews must be structured and well-prepared in advance. Their careful preparation, including the preparation of checklists, if necessary, helps to increase the productivity of interviews. The interviewee should be encouraged to feel at ease and open to communication. Good practice in interviews is similar to that used in any type of audit.

One of the best ways to track and understand what is happening is to practically observe the activities. Such techniques help the auditor gain evidence about assets and can be instrumental in collecting evidence about how employees comply with procedures. By careful observation, the auditors try to formulate an initial opinion on the revised activity and behaviors. Inspecting the processes during their actual conduct will give the auditor the opportunity to understand them and provides them with credibility when discussing certain issues with the audited structure. It should be noted, however, that mere observation is not sufficient to substantiate conclusions on certain issues that have arisen over a period of time.

In the case of performance auditing, case study is an effective way to collect, analyze, and present information. Case studies involve a rigorous examination of a representative selection of events, transactions or articles, in order to understand and quantify the program or activity as a whole. The method is based on evaluating the efficiency of different services by analyzing a sample of cases in order to obtain internal information on the exact way of carrying out an activity.

The purpose of performance audit is to collect the necessary quality and quantity of evidence that allows reasonable conclusions to be drawn about how the organization achieves Resource Use Optimization.

For this reason, the main task at this stage of the performance audit is the collection and analysis of evidence. They should focus on the most important aspects of Resource Optimization.

Auditors should be given the right of access to the documents and information they deem necessary for the purpose of the performance audit engagement at all times.

It is of paramount importance that the evidence collected are sufficient to lead a reasonable person to the same conclusion as the auditor. Insufficient evidence can lead to wrong conclusions.

Obtaining and analyzing evidence is the most important aspect of any performance audit. Auditors should find the categories of evidence they intend to use in a particular audit. Such evidence can be obtained, for example, through interviews, observation or analysis of evidence. The sources can be internal and external.

All performance audit missions will aim at preparing the internal audit report, which is the way to provide managers with independent information, solutions, and assurances regarding the economy, efficiency and effectiveness of the use of public funds by audited entities.

\section{Conclusions}

We appreciate that, at the level of the military organization, the internal public audit represents a set of activities that take place within its own structures, these having a well-defined purpose regarding the military system in terms of managerial, logistical, economic, financial, technical or decision-making aspects. At the same time, it can be said that the performance audit must provide top management with information, assurance and independent opinions regarding the achievement of the desired results and the management of resources used to achieve these results under the conditions of the " 3 Es" 
(economy, efficiency and effectiveness) to identify measures to improve the performance of the military organization and to optimize the use of resources. Therefore, we conclude that the performance audit missions can prove to be particularly valuable both at the level of the Ministry of National Defense and at national level, as they can provide an image of the performance of the institutional management. Thus, the recommendations and solutions offered by auditors must contribute to strengthening the stability of the military organization, to achieving its objectives, both domestically and internationally, by anticipation and proper risk management, optimal use of allocated resources and compliance with the existing legal framework. The internal auditor is therefore a creator of added value, through the savings it generates, the opportunities it creates and the losses of value it prevents, through a continuous monitoring and control of the entire activity of the organization.

\section{References List}

[1] https://na.theiia.org/standards-guidance/mandatory guidance/Pages/Definition-of-InternalAuditing.aspx.

[2] M. Ghiţă, M. Sprânceană, Auditul intern al instituţiilor publice, București, Tribuna Economică Publishing House, 2004, p.22.

[3] Government Decision no. 1259/2012; for the approval of the Norms regarding the coordination and development of the national attestation processes and of continuous professional training of the internal auditors from the public sector and of the natural persons.

[4] Romanian Government Decision no. 1.086/2013. 